\title{
Railway Long-span Continuous Beam-arch Bridge Combining Joint Stress Distribution Rules
}

\author{
DANG Xin ${ }^{1,}$ a \\ ${ }^{1}$ School of Civil Engineering, Central South University, Changsha, China \\ ${ }^{a}$ Csudangxin@yahoo.com
}

\begin{abstract}
Keywords: Bridge engineering; Railway engineering; beam-arch bridge; beam-arch joint; joints mechanical analysis

Abstract.On the background of Lanzhou-Chongqing railway Guangyuan Jialing river $(82+172+82)$ $\mathrm{m}$ long-span continuous beam-arch combination bridge, the beam-arch joint stress distribution rules of a railway continuous beam-arch bridge has been studied, which the main span is over $150 \mathrm{~m}$, the construction and services stages are separated.By taking a finite element analysis which whole first and local second, a whole bridge three-dimensional model has been established. After that, the most typical worst loading cases of beam-arch combining joint construction and services stages have been determined. A detailed finite element model of beam-arch combining site has been established, the stress field distribution rules and its main influencing factors have been investigated, and suggestions about optimization in design are presented. Researches show that, under the typical worst-cases of load, beam-arch combining site has reasonable force, and mainly dominated by longitudinal compression; Stress concentration appears primarily in the support and the corner between the arch foot and No.0 block with local tensile stress overrun; The tensile stress in the roof and floor is $0.30 \sim 1.27 \mathrm{MPa}$; the contribution rate of secondary dead load, live load and additional force to stress respectively are $22.1 \%, 23.5 \%$ and $11.2 \%$; With regard to large tensile stress area such as the arch foot stiffness transition section and the juncture between skewback and arch springing, strengthening measure such as ease the transition section should be taken.
\end{abstract}

\section{Introduction}

In China, beam-arch combined bridges have been widely used in practical engineering for recent years[1-2]. Continuous beam-arch combination bridge can valid combine continuous beam and stiffened arch, which as carriageway plate, continuous beam could directly bear live load, and arch has good bearing capacity, structural stiffness and usage rate of material are high, too.

The design of beam-arch combining joint is a key part of long-span continuous beam-arch bridge. It's mechanical performance will affect span ability and load capacity of the full bridge. Combining joint not only need to bear the preload of central bearing diaphragm, but also undertake support reaction, prestress of continuous beam , moment and thrust of tie bar and $\operatorname{arch}[3]$.

In China, many scholars have deep study in highway beam-arch combining joint[4-6], but compare to highway continuous beam-arch combination bridge, railway has the characteristics of big live load and high structural stiffness, stress conditions are more complex. So far, for a single cell and single box section beam-arch combination bridge which main span is over $150 \mathrm{~m}$, researches of stress distribution rules were relatively less.

In order to research the mechanical characteristic of long-span continuous beam-arch bridge combining joint, by using a space finite element software, a double-line railway $(82+172+82) \mathrm{m}$ long-span continuous beam-arch bridge model has been established. After that, the most typical load cases have been determined, boundary loads of local finite element model has been extracted. By using a large general FEM software, stress field distribution and it' s major influence factors of the combining joint have been investigated, several strengthening measures have been taken. 


\section{Engineering Background}

Guangyuan Jialing River specially long span bridge locate in Guangyuan City of Sichuan Province China. It is a prestressed concrete continuous beam- concrete filled steel tube arch combining bridge structure, see figure 1 below.
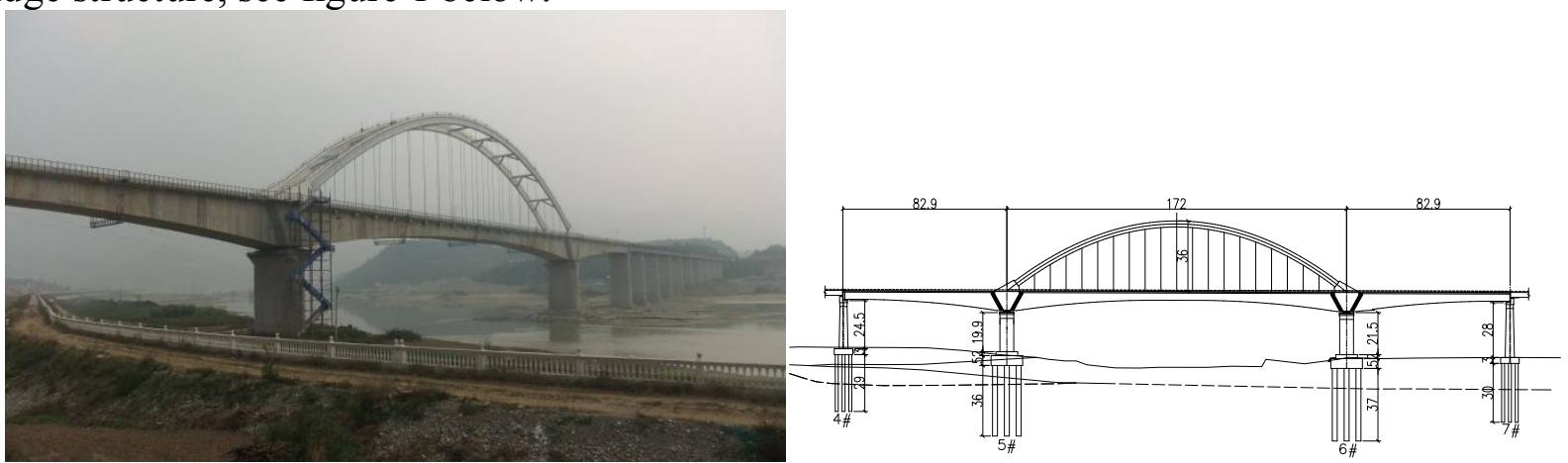

Fig.1 General arrangement diagram of Guangyuan Jialing river specially long span bridge(m)

Concrete mark C55, steel grade Q345. For twin-box single cross sections beam-arch bridge, in consideration of inharmonious stress situations between girder and both arch ribs, this bridge take single box single chamber section can reduce horizontal internal force of girder section. Combining joint including 0\#,1\# and 2\# block, longitudinal length is $26 \mathrm{~m}$, bridge deck width is $13 \mathrm{~m}$, crosswise thicken part width is $1.6 \mathrm{~m}$, transom thickness is $4.2 \mathrm{~m}$, skewback length is $12.8 \mathrm{~m}$, altitude is $5.51 \mathrm{~m}$, combining joint size see figure 2 below.

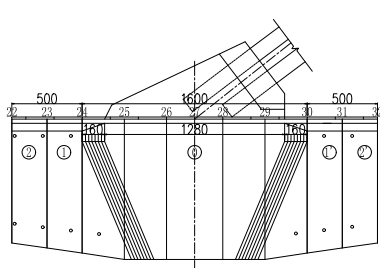

(a) front elevation

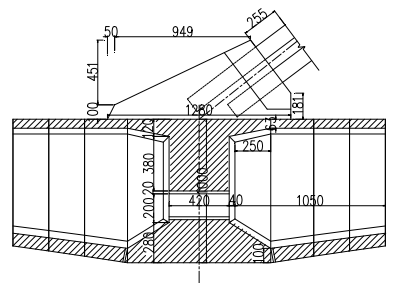

(b) right section

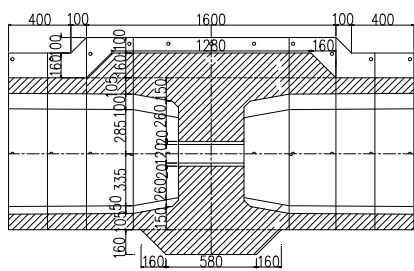

(c) plan section

Fig. 2 structural map of beam-arch combining site $(\mathrm{cm})$

\section{Global Model Analysis}

First, based on a space finite element software ,a continuous beam-arch bridge model has been established. Girder, arch rib and waling are simulated by beam element, suspender are simulated by truss element,see figure 3 .

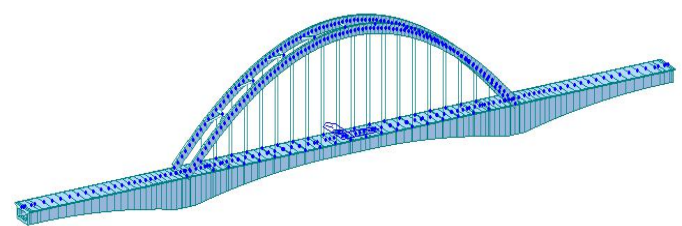

Fig.3 Whole bridge finite element calculation model construction stage

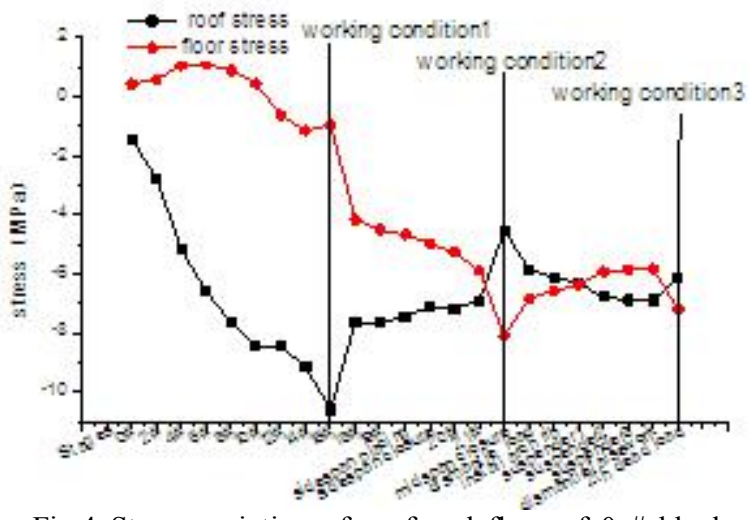

Fig.4 Stress variation of roof and floor of 0 \# block, each

Concrete density 26.5 , steel density 78.5 ,steel-tube concrete density 23.5 , secondary dead load 181 . Foundation settlement measurement of services stage take the equal settlement difference value of adjacent two fulcrum, which is $\leq 2.0$. Laying double line ballast track, calculating live load 
is China railway standard loading, impact coefficient 1.064 . Temperature calculation take overall warming $20^{\circ} \mathrm{C}$, overall cooling $20^{\circ} \mathrm{C}$, temperature gradient follow the stipulations of "China fundamental code for design on railway bridge and culvert"[7]. Lateral swaying force of train, force due to braking and accelerating put on the girder as concentrated forces respectively. Arch rib wind force put on the arch as even load breadthwise.

Based on 5\# pier all construction procedures stress theoretical value analysis of combining joint box-girder section, worst load cases of construction stage can be determined. Stress change of combining joint each stage see as figure 4 below.

At services stage, load stresses of combining joint boundary section should be analysed. As a result, there are two cases - main forces envelope and main + additional force envelope have been calculated. Main envelope including dead load, live load and settlement. Main + additional force envelope including main forces, temperature force, forces due to breaking and accelerating, arch rib crosswise wind force and lateral swaying force of train.

By calculating static load cases, load stresses of combining joint boundary section can be got, and it will be equivalently put on the local model, see as table 1 , the local model loading schematic diagram see as figure 5 .

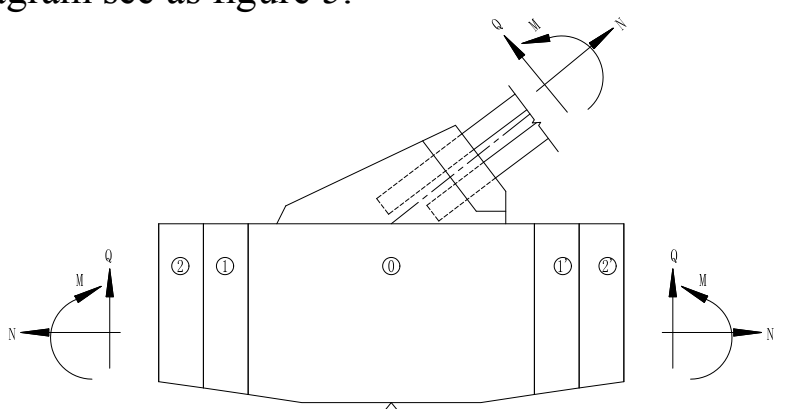

Fig.5 Local model loading schematic diagram

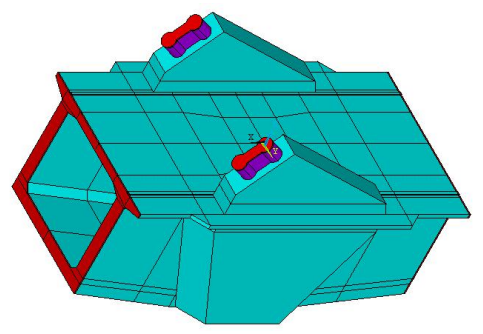

Fig.6 Local finite element model schematic diagram

Tab.1 Equivalent boundary force of beam-arch combining site finite element model

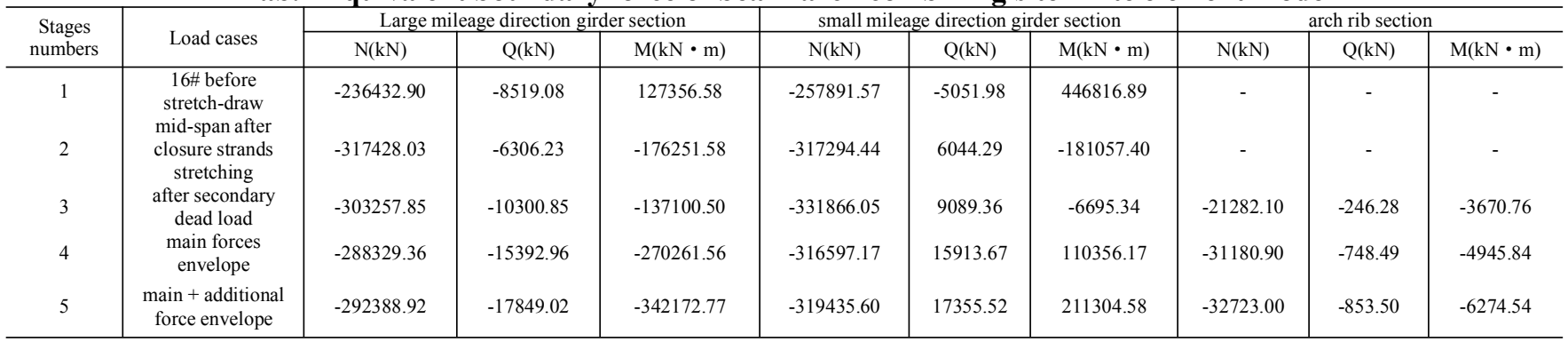

\section{Stress distribution laws of combining joint}

\section{Refined finite element analysis model}

After the establishment of the entire bridge, a combining joint refined model has been built by general finite element software, which based on the saint venant principle[8], and loss of prestressed effect has been considered[9-10]. Extending main girder 0\#,1\#,2\# block totally $26 \mathrm{~m}$ as a local model analysis object.

By equivalent load method, Axial force, shearing force and bending moment of boundary surface can be put on the model as even loads[11-12]. Refined finite element analysis model see as figure 6 below, which dark area is loading area.

\section{Stress analysis of construction stage}

Working condition one and two of construction stage without arch rib, but skewback involved in the stress distribution of fulcrum section, this is a big difference between continuous beam-arch bridge and common continuous beam bridge. The stress situation is a key issue of construction stage analysis. Stress nephogram and it' s variation situation see as figure 7. 


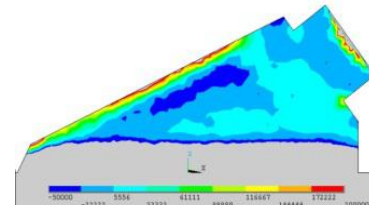

(a) condition one

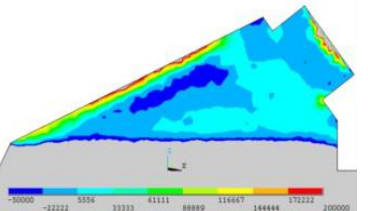

(b) condition two

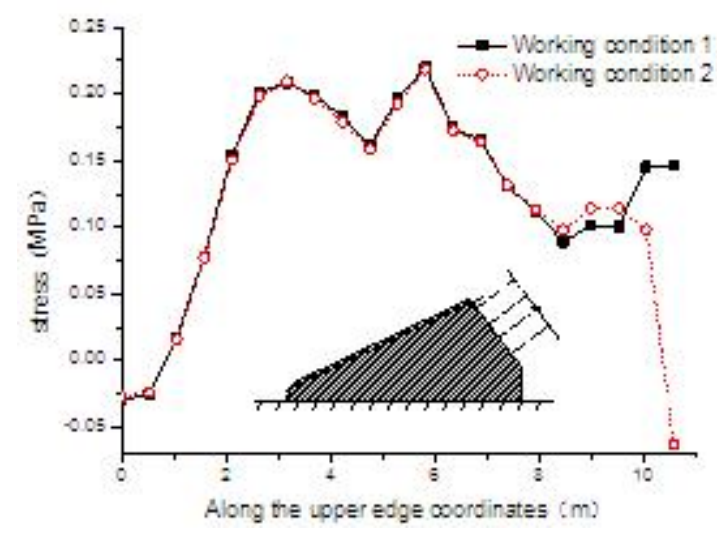

(c) variation of stresses along the skewback vertical
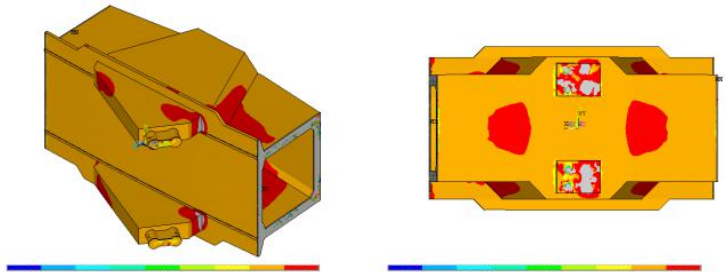

Fig. 8 Stress nephogram of third working condition $(\mathrm{Pa})$

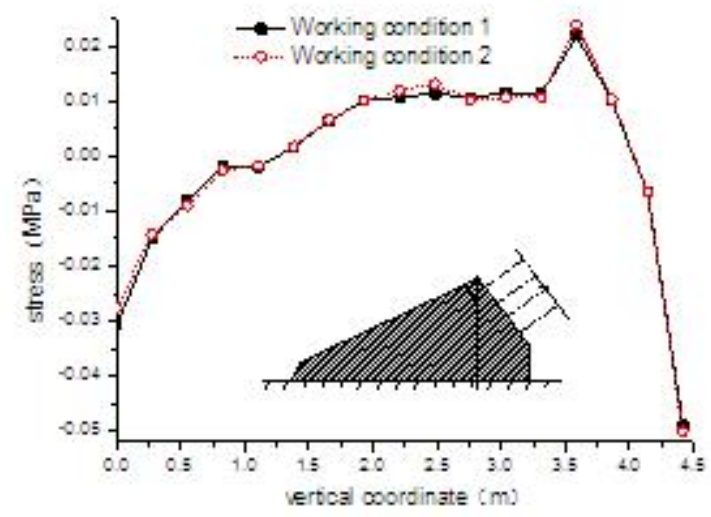

(d) variation of vertical stresses

Fig.7 The stress distribution of skewback in the construction stage

Skewback in the negative moment region, show a small tensile stress. The stress along the skewback vertical is small, which the biggest tensile stress is only $0.02 \mathrm{MPa}$, but stress along the skewback top edge is much bigger, which can reach $0.22 \mathrm{MPa}$.In most area, concrete is in the compressive stress state. Due to the restraint of the support, it show a stress concentration, which local stress is higher than 4.0MPa. Due to structural reasons, combining corner between skewback and $0 \#$ block show a stress concentration, tensile stress can reach $3.0 \mathrm{MPa}$. The principal tensile stress state stress nephogram of working condition 3 see as figure 8 .

\section{Stress analysis of services stage}

In services stage, the principal tensile stress state stress nephogram of working condition 5 see as figure 9.

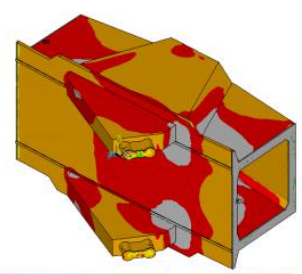

Fig.9 Stress nephogram of third working condition $(\mathrm{Pa})$
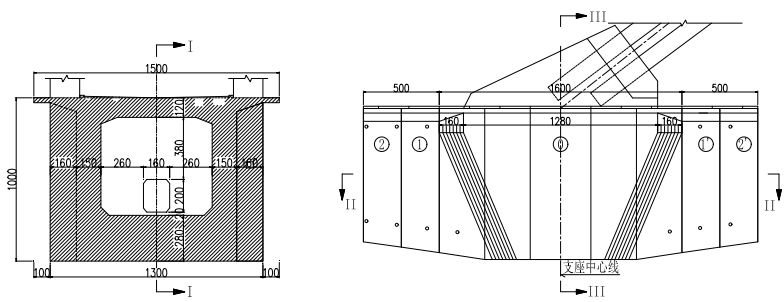

Fig.10 Schematic diagram of cross section

Most concrete of combining joint is in the compression situation. Large tensile stress show near support and structure bulges. Cause of constraint of support, it' $\mathrm{s}$ tensile can reach 5.0MPa.0\#block superior border lie in negative moment tensile stress region, tensile stress evenly distributed, and all below $1.8 \mathrm{MPa}$. Tensile stress of skewback is obviously less than 0\#block superior border, as a result of the pressure action from arch to the 0\#block.

Stress distribution of skewback is uniformity, tensile stress region is small, most of them below 1.0MPa. Geometric mutation area between skewback and 0\# block show a high tensile stress. Most area of skewback concrete is in compression state, concrete stress in steel pipe is stabilized. 


\section{Representative section mechanics property analysis of combining joint}

In order to research the longitudinal, transverse and vertical stress distribution laws of combining joint,respectively analysis had bee for it' $s$ typical cross section of three directions. The position of the section of intercepting diagram shown in figure 10.Among them, I-I 、 II-II and III-III respectively, for the longitudinal, transverse and vertical section.

In order to study the stress distribution of three typical cross sections, the paths of the I-I cross section roof and floor axes, II-II cross section of the support centerline and III-III cross section of box beam vertical centerline were defined by using the path command. The stress distribution of several working conditions is shown in Figure 11.

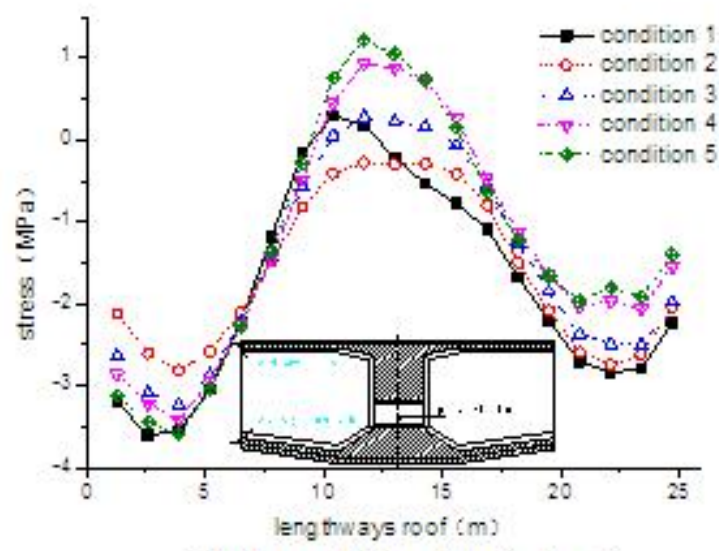

(a) The roof's longitudinal axis

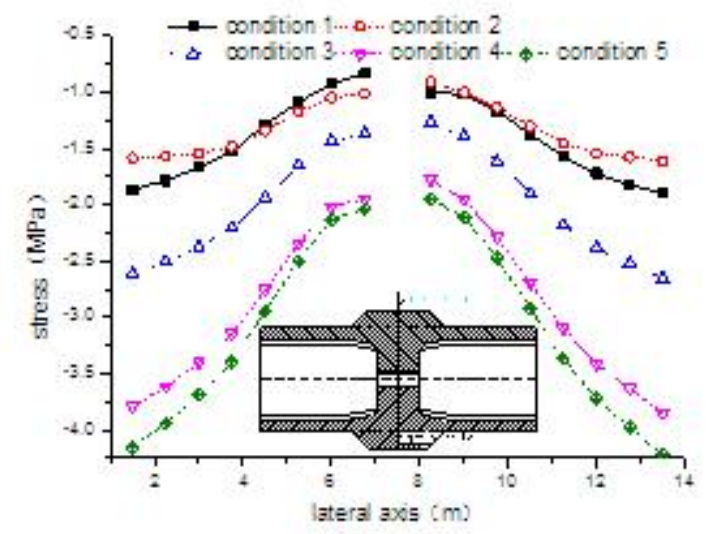

(c) Lateral axis

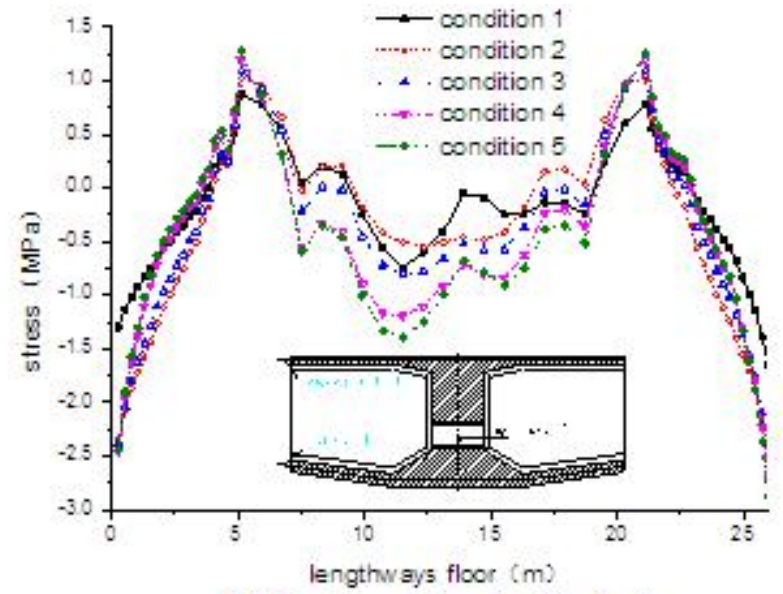

(b) The floor's longitudinal axis

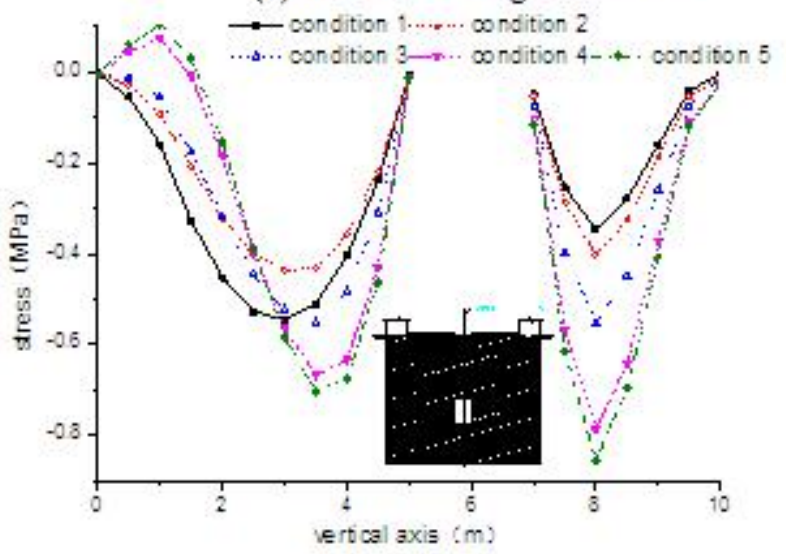

(d) Vertical axis

Fig. 11 Stress changes of several kinds of working conditions

As shown in the chart above, with regard to the longitudinal roof, the tensile stress shows near the support centerline except working condition 2, and the construction stage shows a small tensile stress, which is less than $0.30 \mathrm{MPa}$; while the tensile stress is larger at the service stage, and the tensile stress of working condition 5 is the largest, which can reach $1.23 \mathrm{MPa}$.

As the centerline of support for axis, the floor longitudinal stress displays a symmetric distribution, where in the floor the thickness variation near the beam shows a small tensile stress, while the others are in the compressive stress state, and the largest tensile stress of working condition 1 to 5 is increasing gradually, and the largest can reach $1.27 \mathrm{MPa}$.

The largest roof tensile stresses of five working conditions arise near the centerline of the support, the largest floor tensile stress shows during the beam section thickness variation near the beam; the largest transverse compressive stresses show near the lateral edge of the model, and the largest vertical compressive stresses show in the access hole and in the middle of the upper and lower edges of the cross-section. The largest tensile and compressive stress variation of each working condition is show in Figure 12. 


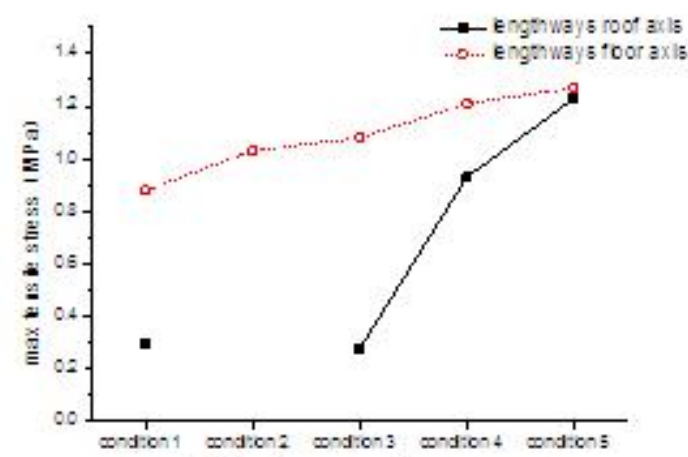

(a)Maximum tensile stress

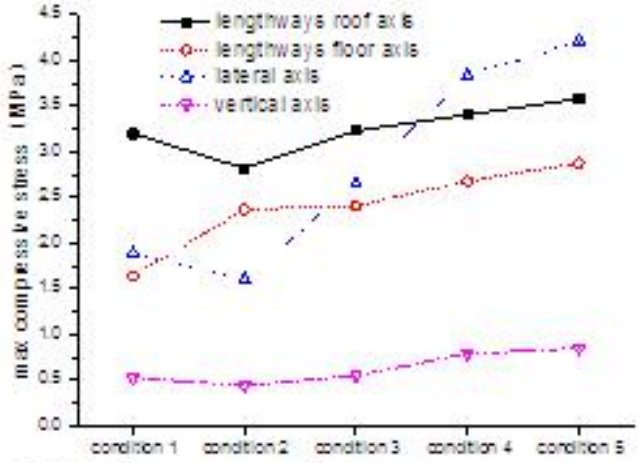

(b) Maximum compressive stress

Fig.12 maximum tensile stress and compressive stress of each working condition

As shown in the chart above, an overall upward trend shows in all stresses of each working condition. Compared to working condition 2, working condition 3 added the secondary dead load, the best values of each section stress raise by an average of $22.1 \%$, and the secondary dead load has a greater contribution rate to stress; similarly, the live load of train also has a greater contribution rate to stress, and the stress raises by an average of $23.5 \%$; working condition 5 adds temperature force, forces due to breaking and accelerating, arch rib crosswise wind force and lateral swaying force of train, each section stress raises by an average of $11.2 \%$, and the additional forces have a smaller contribution rate to stress.

\section{Beam-arch combining joint stress optimization measures}

Due to the stiffness mutation of beam-arch combining joint, it' easy to cause stress concentration, leading to local concrete cracking in the stress weak areas. For no large stress concentration occurring in these regions under the most unfavorable load, stress peaks shall meet regulatory requirements. The partial construction of the local finite element model will be optimized in this section.

For the larger stiffness areas in the interaction region between arch and main beam, interaction region between thickened block at the foot of arch and main beam, smooth the structural edges, and the model comparisons of optimization before and after are show in Figure 13, when working condition 5 is projected onto the cross-section, the stress nephogram comparison of optimization before and after is shown in Figure 14.

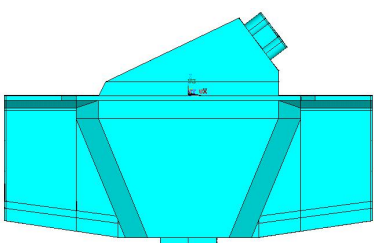

(a) Before

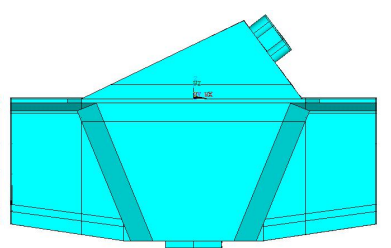

(b) After

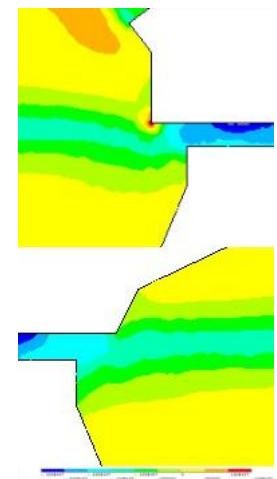

(a) Before

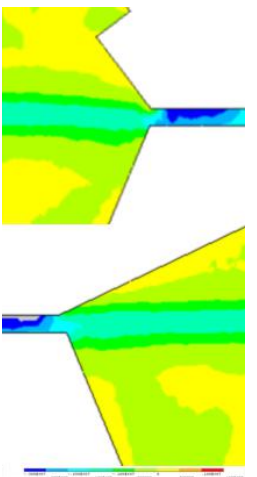

(b) After

Fig.13 Comparative model diagram of optimization before and after Fig.14 Stress contrast figure of optimization before and after

After smooth processing of sharp between structural arch and thickened region, there is less increase in concrete and little change of structural weight. As is shown in the chart above, the overall associativity between skewback and beam is enhanced, easing stress concentration phenomenon. Before optimization, the largest tensile stress at the skewback sharp can reach 1.0MPa; after optimizing, the largest tensile stress reduces to $0.7 \mathrm{MPa}$, which is $30 \%$ less than that before. 


\section{Conclusions}

(1)With regard to a $(82+172+82) \mathrm{m}$ span continuous beam-arch bridge, each controlling cross section stress shall meet the design specifications at the construction and service stages, and beam concrete stress shall be within the safe range; with regard to the local model of beam arch combination site, in the most typical worst-cases of load at the construction and service stage, the supports, combining corner between skewback and 0\# block and the corresponding flange root thickened corner show a stress concentration, wherein local tensile stress of combining corner between skewback and $0 \#$ block is $5.0 \mathrm{MPa}$, beyond the specified limits of tensile stress.

(2) $0.30 \sim 1.23 \mathrm{MPa}$ of tensile stress of local model roof shows near the centerline of the support; as the centerline of support for axis, the floor stress displays a symmetric distribution, where in the largest tensile stress of root thickness variation near the beam can reach $1.27 \mathrm{MPa}$. Stress curves of horizontal and vertical axes are smooth, with no tensile stress. The contribution rate of secondary dead load, live load and additional force to stress are respectively $22.1 \%, 23.5 \%$ and $11.2 \%$.

(3)large tensile stress appear due to the concentration of stress, such as the arch foot stiffness transition section, after easing the transition period, the largest tensile stress can reduce by $30 \%$ 。

\section{References}

[1] PEI Ruo juan, ZHONG Jin dong, LI Chao feng. High speed railway arch bridge arch foot stress analysis[J]. Journal of Railway Engineering Society. 2002(3): 23-28.

[2] LI Zi-te. Mechanical Properties Study for Beam-arch-binding site of Continuous Beam-arch Composite Bridge[D]. Lanzhou Jiaotong University, 2009.

[3] YAN Hai, ZENG Ming-geng, FANG-Li-chu, Large span arc bridge arch feet node local stress analysis[C]. China highway society computer application annual conference 2002 academic papers. 2002: 69-73.

[4] XUE Dong-yan, LIU Yu-qing, HE Jun, et al .Experimental study and numerical analysis of a composite truss joint [J]. Journal of Constructional Steel Research, 2011,67(6): 957-964

[5] PENG Gui-han, CHEN Bao-chun, SUN Chao. FEM stress analysis of springing joint for CFST and rigid frame tied through arch bridge[J]. Journal of Fuzhou University (Natural Science).2007,35(1): 85-88.

[6] YAO Jun-fang. Yongxiu Frame arc bridge research and just local stress analysis of dynamic and static force characteristics[D]. Central South University, 2009.

[7] TB10002.1-2005, Fundamental code for design on railway bridge and culvert[S]. China railway Publishing House, Beijing, 2005.

[8] DONG Hua-xian. Railway continuous beam arch combination bridge space mechanical performance analysis[D]. Central South University, 2009.

[9] Gong lian Dai, Miao Su, Bin Yan. Case Study of Twin Cable-Stayed Bridges for High-Speed Railway in China: Design, Analysis and Construction[J]. Structural Engineering International, 24(3): 396-401.

[10] Gong Jun-hu. Study on mechanical characteristics of combines bridge of V-shaped pier rigid-frame and arch structure[J]. Southwest Jiaotong Un1versity, 2009.

[11] CHENG Jia-de. Local Stress Study for Arch Springing of Large Span Continuous Beam-arch Composite Bridge[D]. Lanzhou Jiaotong University, 2013.

[12] ZHOU Dong. Key techniques of beam arch combination structure design[D]. Central South University, 2011.

[13] ZHAO Xun-gang Test and numerical analysis for arch-beam joint of half-through continuous beam-arch combination bridge with concrete filled steel box arch-ribs[J]. Southwest Jiaotong Un1versity, 2011. 